\title{
The development of a socio-economic model to promote women's empowerment initiatives in the renewable energy sector of South Africa
}

\author{
C.M Adendorff ${ }^{1}$, Harvey Keown ${ }^{2 *}$, Ric Amansure ${ }^{3}$ \\ 1 Nelson Mandela University Business School; ORCiD: https://orcid.org/0000-0002-1520-9072 \\ 2 Nelson Mandela University; ORCiD: https://orcid.org/0000-0001-9175-5465 \\ 3 Nelson Mandela University; ORCiD: https://orcid.org/0000-0002-2082-8353 \\ All at PO Box 77000, Port Elizabeth 6031, South Africa
}

\begin{abstract}
This study investigates the main contributors that can positively influence the socio-economic empowerment of women in the renewable energy sector in the Republic of South Africa, and recommends new and innovative approaches to mainstream gender in the sector. Empirical evidence showed that ethical leadership positively influences good governance and successful women's empowerment. The results also indicated that social investment and broad-based black economic empowerment positively influence successful women's empowerment. Finally, the results indicated that sustainable programmes are a positive contributing factor to good governance. However, the respondents did not consider stakeholder engagement statistically significant to good governance or successful women's empowerment. This study also has the potential to contribute to the improvement of impoverished communities in South Africa and elsewhere.
\end{abstract}

Keywords: socio-economic empowerment; empowerment of women; mainstream gender; renewable energy; local economic development.

\section{Highlights:}

- The structural equation modelling examined the socio-economic empowerment in South Africa.

- The empirical results revealed that ethical leadership positively influences successful women's empowerment.

- This study has the potential to contribute to future approaches and developments to mainstream gender.

Journal of Energy in Southern Africa 31(2): 34-47

DOI: http://dx.doi.org/10.17159/2413-3051/2020/v31i2a6166

This work is licensed under a Creative Commons Attribution-ShareAlike 4.0 International Licence

Published by the Energy Research Centre, University of Cape Town ISSN: 2413-3051

https://journals. assaf.org.za/jesa

Sponsored by the Department of Science and Technology

* Corresponding author: Tel: +27 83380 4991;

email: h.keown@af-sd.com 


\section{Introduction}

There is a complexity associated with gender equality and women's empowerment in the Republic of South Africa. This complexity is compounded due to the multi-dimensional nature of the problem, and the stakeholders that are spread across sectors like the public organs of state, private sector, organised labour, and civil society. The challenge is therefore to identify and quantify the drivers of success needed to achieve sustainable socio-economic empowerment of women at all levels of society. This challenge was addressed by focusing on the renewable energy value-chain.

PricewaterhouseCoopers (2016) conducted a study that researched 2500 of the most significant global companies. The findings indicated that, of the 359 permanent or interim CEOs appointed in 2015 worldwide, only ten were female. At $2.8 \%$ of all new $\mathrm{CEO}$, this was the lowest rate since 2011 (McGregor, 2016). An International Business Report of 2015, which surveyed 5520 businesses in 36 economies, revealed that of the 200 South African business executives surveyed, women only occupied $23 \%$ of the senior positions. The same report stated that $39 \%$ of businesses did not have any women in leadership positions (Kilian, 2016). The Johannesburg Stock Exchange recognises that during the past decade there has been little change in the proportion of women in senior positions of listed companies and has changed its listing requirements to encourage listed companies to disclose female representation. The disclosure would encourage companies to increase the nature and pace of gender transformation (Kilian, 2016). According to Eberhard et al. (2014), the South African Renewable Energy Independent Power Producer Procurement Programme (REIPPPP), a competitive tender process to facilitate private sector investment into grid-connected renewable energy (RE) generation, is one the most effective policy instruments to accelerate and sustain private investment within the renewable energy sector. Through the economic development funds generated by the independent power producers, South Africa has the potential to substantially contribute to mainstreaming gender and be a catalyst to transition women entrepreneurs to become owner-operators of their power generation facilities (Eberhard et al. 2014; Kilian, 2016; Pricewater-houseCoopers, 2016).

Studies like those cited indicate that identifying the factors that influence the success of new and sustainable women's empowerment initiatives is complex and elusive because of the complex nature of mainstreaming gender in South Africa. The present study investigated the status of women in business at international, continental, and country levels. Although the focus was on the economic empowerment of women in the RE sector, it is equally applicable to the mining, manufacturing, and agricultural sectors. The intention of this study was, therefore, to provide a possible blueprint to mainstreaming gender and sustainable women's empowerment. The entry point was the body of knowledge that already existed within the United Nations, the World Bank, the World Economic Forum, the Global Environmental Facility, and other relevant institutions. The main contributors and variables that could positively influence the socio-economic empowerment of women initiatives in the RE sector were examined.

\section{Methodology}

This study can be described as theoretical and model-building, where the proposed theoretical model was supported by the collection of empirical data from various sources:

- semi-structured interviews with policymakers, influencers of funding and implementation, and energy sector decision-makers;

- structured interviews with gender experts;

- researcher field notes; and project experience; and

- publications on women's empowerment.

The collected data was analysed and empirically tested using an advanced statistical technique called structural equation modelling (SEM) (Wothke, 2010). It was used to analyse simultaneous multiple independent relationships against the dependent variable: the perceived success of socio-economic empowerment initiatives of women in the RE sector in South Africa. The technique can be used in real-life situations using quantitative data gathering and analysis in a format compatible with the proposed theoretical research model (Hair et al. 2009). SEM also allows for both exploratory and confirmatory modelling, which means it is suited to both model testing and model development (Wothke, 2010). Several factors from the preliminary literature review informed the conceptual model, which was then empirically interrogated by utilising the SEM technique. The study was divided into three phases: data collection, analysis, and the extrapolation of the new hypothesis (Walwyn \& Buys, 2014). The dependent variable, the socio-economic empowerment of women and the perceived success of women's empowerment in the sector was examined. The intervening variable articulated the importance of corporate governance. The independent vari- 
ables consisted of the need for the socio-economic development, the importance of stakeholder engagement, requirement of strategic acumen, the importance of strategic planning, need for broad-based black economic empowerment, benefit of executive leadership, advantage of change management, requirement for executive education, criticality of fund management, and the importance of corporate culture. The hypothesised inter-relationships presented in Figure 1 provide a graphical representation of the theoretical model, which presents the independent, intervening and dependent variables that positively influence the socio-economic empowerment of women in the sector.

The process of operationalising the variables included defining the variables of interest operationally, and developing valid and reliable scales of measurement. Although the definitions do not guarantee the accuracy, they assisted the researcher to comprehend an abstract construct using concrete variables (Babbie, 2010). These variables are discussed in detail below.

\section{Socio-economic development}

Development can be defined as a planned and comprehensive economic, social, cultural, and political process in a defined geographic area,

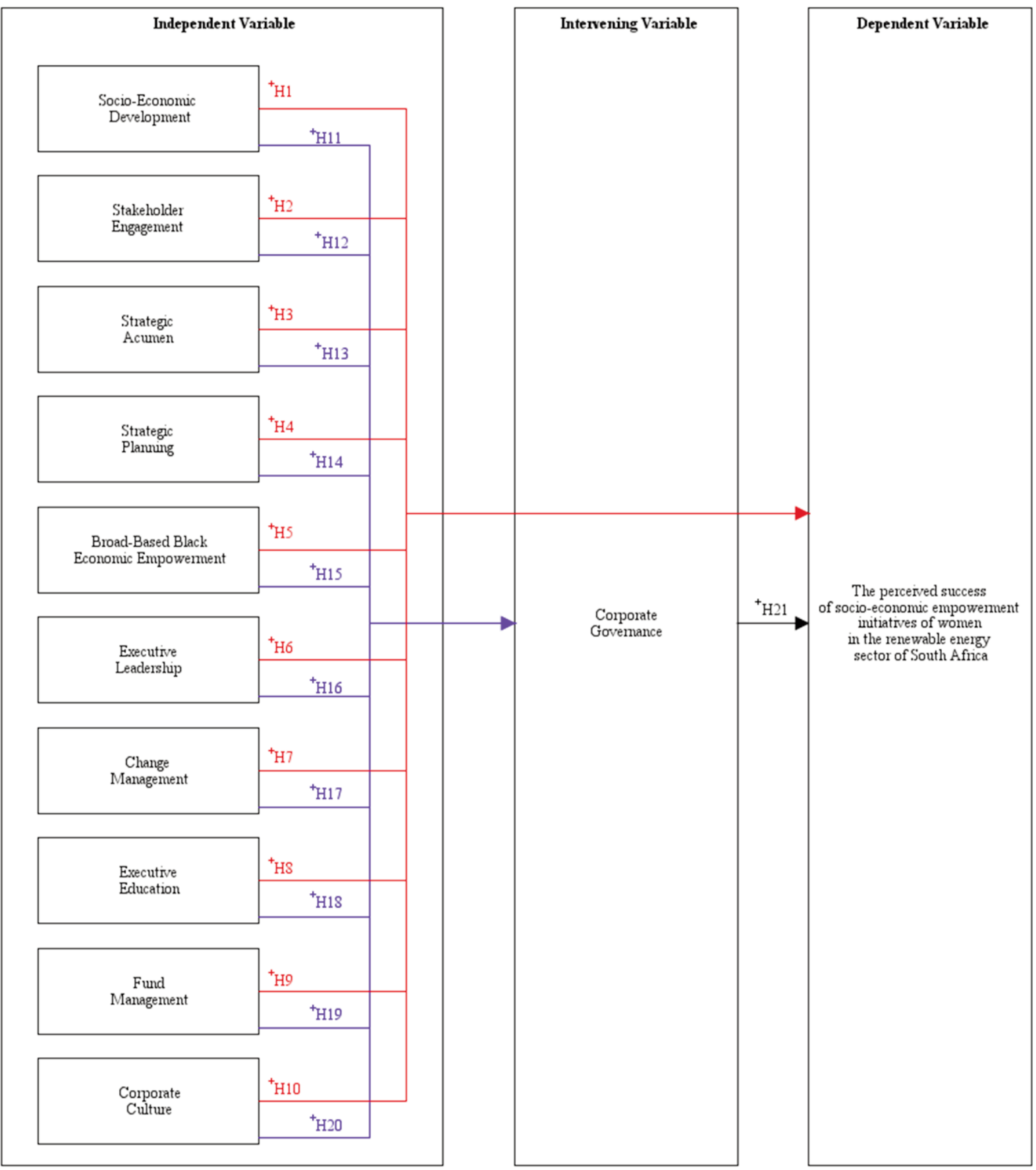

Figure 1: Theoretical socio-economic development model, where $+\mathrm{H}$ is the hypothesised variable. Source: Own construction 
one that is based on rights and ecologically oriented, and that aims to continually improve the well-being of the entire population (Fritz, 2001). Socio-economic development means professional intervention with the intention of improving socio-economic conditions on several levels: individual and group empowerment, conflict resolution, institution-building, community-building, nation-building, region-building, and world-building (Fritz, 2001). Socio-economic development was therefore considered as a process that seeks to identify the social and the economic needs within a community as well as encouraging capacity building for more significant participation, improved planning processes, greater decision-making power and control of all contributing transformative actions (Eberhard et al. 2014; Fritz, 2001; Department of Trade and Industry, 2013; Presence, 2018).

\section{Stakeholder engagement}

As described by the International Finance Corporation (2007), consultation activities that are mainly driven by rules and requirements invariably become a one-time agenda of public meetings that revolve around environmental and social assessment processes. This type of consultation normally does not progress beyond the project planning phase, is seldom integrated into core business activities, and lacks monitoring and evaluation of the effectiveness of developing constructive working relationships. The emerging terminology to describe stakeholder engagement describes a broader, more inclusive, ongoing process of engagement between the company; and interested and affected parties; and spans a range of activities and approaches over the entire life of a project. In the context of this study, stakeholder engagement refers to the internal and external stakeholders that have an influence on the economic empowerment of women within the RE sector. A stakeholder can be further defined as a party that has an interest in a company, the community, the economic empowerment of women in these communities, representing the government or any other interested party. A company can have a diverse set of stakeholders, both internal and external. The internal stakeholders of the company are its investors, employees, service providers, and customers, while the external ones are civil society (community), government, organised labour or service providers of non-core initiatives (International Finance Corporation, 2007; Creamer, 2018; BusinessTech, 2018). Therefore, different stakeholders have different levels of engagement, decision-making power and influence at differing stages of the project lifecycle.

\section{Strategic acumen}

Business acumen can be defined as eagerness and speed in comprehending and deciding on a business environment, which implies having the business view to get important information about a situation. Strategic acumen includes the ability to focus on the key strategic objectives and to have the experience to articulate the various scenarios for a solution (Grillo, 2015; Prince, 2008; Ragas, 2019). Strategic acumen is intricately linked with leadership characteristics like authenticity, decisiveness, vision, humility, talent selection, coaching and feedback - characteristics that promote trust between leadership and their management team (Erb, 2008). Therefore, strategic acumen has been considered as a process in which people think about, consider and create the future for themselves and others. Strategic acumen includes the ability to develop practical plans and interventions that are aligned with the strategic objectives of the company within a socio-economic situation. Strategic acumen helps decision-makers to review policy issues, perform long-term planning, set goals and determine priorities, and identify potential risks and opportunities.

\section{Strategic planning}

Strategic planning was suggested by Kenny (2016) to be a process whereby companies determine their vision for the future, identify their goals and objectives, outline the activities that will achieve the stated objectives, are prepared to take calculated risks and, most importantly, put in place the monitoring and evaluation plan that will guide the achievement of their objectives. Strategic planning also takes into consideration the human, financial and any additional resource requirements to achieve the strategic direction.

\section{Broad-Based Black Economic Empowerment}

Broad-Based Black Economic Empowerment (B-BBEE) is a policy that was initiated by the South African government to address the gross inequality in South Africa by redistributing the wealth across as broad a spectrum of previously disadvantaged South Africans (Department of Trade and Industry, 2013). The B-BBEE Act (Act 53 of 2003) was premised on the fact that decades of systemic racism contributed to the socio-economic challenges that the country faces (Department of Trade and Industry, 2013). The $\mathrm{B}-\mathrm{BBEE}$ codes provide a guidebook for the measurement of ownership, management control, employment, skills development, preferential procurement, enterprise development, socio-economic development and qualifying small enterprises. The economic development 
requirements of the REIPPPP in South Africa have been controversial, confusing, and expensive for bidders to respond to (Eberhard et al. 2014). Executive leaders that are visionary and have an appreciation of the business and reputational risks to their companies and shareholders tend to go beyond compliance when implementing socio-economic development initiatives (Department of Trade and Industry, 2013; Eberhard et al. 2014). This visionary approach by these executive leaders tends to avoid a compliance-driven tick-box exercise.

\section{Executive leadership}

There should be a comprehensive definition and practical ways to measure leadership performance, as leadership is about establishing an enduring and flexible architecture that facilitates performance and achieves the desired results. A good or bad strategy is based on measurable results, meaning that results are the measurement. The role of leaders is to provide precise definition and differentiation, eliminate the many leadership positions that are artificially created and not needed, and measure performance rather than potential (Drotter, 2003). Executive leadership can therefore be defined as the leadership of a company with the expertise to define the company's strategic objectives and to articulate practical ways to measure leadership performance. Executive leadership also includes the ability to eliminate unnecessary leadership positions, the experience to establish flexible and enduring systems to facilitate performance, and the depth to have a precise definition of the leadership role (Drotter, 2003; Engelbrecht, 2009; Global Environmental Facility, 2017; Zinn, 2017).

\section{Change management}

Extensive effort has been invested in developing methodologies and approaches to apply change management concepts to managing the development and implementation of projects and programmes. The primary focus being to prepare the parties impacted by these initiatives to embrace the change that results from a project's activities (Harrington and Voehl, 2015). Change management theories and philosophies have both an emotional and situational component. The methods for managing each of these change management components was based by Campbell (2008) on an eight-step model: developing earnestness, constructing a conducting team, formulating a vision, communicating for buy-in, facilitating action, creating short-term victories, doing no let-up, and making it stick. Change management has been defined as an approach to transition individuals, teams, and companies by preparing these parties to embrace the change that results from project implementation. It is intended to guide or significantly reshape a company or community by using change management methods to re-direct the use of human and financial resources, processes, or other operating modes. It spans several disciplines from behavioural and social sciences, information technology and business solutions (Campbell, 2008; Harrington and Voehl, 2015).

\section{Executive education}

Executive education refers to the importance of education of executives and decision-makers and how their perspectives influence their decision-making as it relates to the non-core business activities linked to the community and socio-economic development initiatives, as described by Marsh (2014) and Martín (2016). The premise is that socio-economic development is non-core, misunderstood, and creates a significant degree of discomfort for executive management. The consequence is that executive management invariably makes decisions based on their belief systems, their current frame of reference informed by their learnt background, and least-risk approach initiatives. This can, therefore, create a negative bias towards socio-economic development based on their personal paradigm.

\section{Fund management}

Fund management refers to the active financial management, investment, and disbursement of socio-economic development funds (European Commission, 2018; Humentum, 2018; Paramasivan and Subramanian, 2009). As per regulatory requirements, these funds should be invested in economic development activities to promote quality job creation, local manufacturing, investment in community development and black economic empowerment as defined under the REIPPPPs Implementation Agreement (Stands, 2015). There are several key factors that positively influence effective fund management activities: effective corporate governance, sound financial planning, proper budgeting, appropriate financial controls, efficient support systems, and unbiased investment in the target beneficiaries (European Commission, 2018; Humentum, 2018; Paramasivan and Subramanian, 2009).

\section{Corporate culture}

Corporate culture refers to the prevailing culture within a company towards the socio-economic development of the intended beneficiaries. This could be a proactive, long-term 
approach to socio-economic development; or there could be a very narrow, short-term compliance approach. Companies that recognise that they lack the necessary socio-economic development expertise in-house and engage outside advice, potentially deliver more impact through their socio-economic investment (Michael Watkins, 2013; Teasly, 2016; Harrington and Voehl, 2015).

\section{Corporate governance}

Good corporate governance can be considered, as by Engelbrecht (2009) and Hamilton (2003) as the processes to make and implement decisions, with an emphasis on the best possible process for making those decisions. Governance can apply to a company, government, community, governing body or any entity that manages an outcome. Specifically, the good corporate governance and the integrity of the IPP involves their executive leadership, and its shareholders, as it relates to decision-making regarding the obligatory socio-economic development initiatives in the $\mathrm{RE}$ sector.

\section{Women's empowerment}

Women's empowerment can be defined as a process of enhancing the capacity of women or groups of women to make choices and convert these choices into actions and outcomes (World Bank, 2007). During 2016 only 23\% of the senior positions in South African corporations were occupied by women, and 39\% of businesses did not have any women in leadership positions (Kilian, 2016). The socio-economic empowerment of women within the RE sector of South Africa also has a complex stakeholder domain, which includes government, the private sector, organised labour, and civil society. Further to this complexity, the most controversy and uncertainty generated amongst the bidders of the REIPPPP was the reliance on the economic development requirements (Eberhard et al. 2014). Applying the World Bank's defini- tion, women's empowerment in the RE sector can be considered as the processes of enhancing the capacity of individuals or groups, typically indigent groups, to make choices and implement decisions to acquire assets in the sector. The elements that underpin institutional reform are access to information, inclusion and participation, accountability, and local organisational capacity (Eberhard et al. 2014; Kilian, 2016; World Bank, 2007).

\section{Results and discussion 3.1 Data analysis}

This section discusses the factor analysis results, in order to assess the discriminant validity of the model. For the exploratory factor analysis, a total of 243 cases were analysed, no cases were discarded. The pattern matrix is presented in Table 2. To interpret the relevant factors, the initial selection process was accompanied by a rotation of the retained factors (Abdi, 2003). Two primary types of rotation were utilised: orthogonal when there is no correlation between the new axes; and oblique when the new axes are not necessarily orthogonal (Fabrigar and Wegener, 2011). In other words, they were correlated. The rotations were performed in a subspace, i.e. the factor space and the new axes explained less variance than the proposed factors, which computed to be optimum. The component of variance described by the full total subspace after rotation was equivalent to it before rotation, with only changes to the partition of the variance (Kothari, 2004). All the variables in the theoretical model were assessed for discriminant validity using exploratory factor analysis that utilised the principal axis factoring extraction technique with direct quartimin oblique rotation specified as the rotation method. The results of the factor analysis are presented in Table 1 . Seven factors with eigenvalues greater than 1.0 were extracted, explaining $69.09 \%$ of the variance in the data.

The number of factors extracted had not

Table 1: Exploratory factor analysis, variance explained by extracted factors. Source: Own construction

\begin{tabular}{lcccc}
\hline \multicolumn{4}{c}{ Total variance } \\
\hline Factor & Total & $\begin{array}{c}\text { Initial eigenvalues } \\
\text { \% of variance }\end{array}$ & Cumulative \% & $\begin{array}{c}\text { Rotation sums of } \\
\text { squared loadings total }\end{array}$ \\
\hline 1 & 17.490 & 40.674 & 40.674 & 7.491 \\
2 & 3.966 & 9.224 & 49.898 & 5.854 \\
3 & 2.875 & 6.685 & 56.583 & 7.544 \\
4 & 1.660 & 3.860 & 60.444 & 6.881 \\
5 & 1.456 & 3.387 & 63.831 & 12.753 \\
6 & 1.242 & 2.889 & 66.719 & 3.640 \\
7 & 1.019 & 2.369 & 69.088 & 11.219 \\
\hline
\end{tabular}


been specified initially, but the eigenvalues indicated that seven factors were to be extracted. This model was refined using an iterative process of deleting items that did not demonstrate adequate discriminant validity, low loading and cross-loading on more than one factor, and reexecuting the exploratory factor analysis until all the remaining items loaded to a significant extent ( $p \geq 0.350$ ) without cross-loadings. Table 2 presents the most interpretable factor structure, where all items with loadings $<0.350$ were deleted and a total of 43 items were loaded onto seven factors.

From the exploratory factor analysis, there

Table 2: Rotated factor loadings

Source: Own construction.

\begin{tabular}{|c|c|c|c|c|c|c|c|c|}
\hline \multicolumn{9}{|c|}{ Pattern matrix - rotated factor loadings } \\
\hline \multicolumn{2}{|c|}{ Factor } & 1 & 2 & 3 & 4 & 5 & 6 & 7 \\
\hline \multicolumn{2}{|c|}{ Item } & $\begin{array}{c}\text { Social } \\
\text { investment }\end{array}$ & $\begin{array}{l}\text { Stakeholder } \\
\text { engagement }\end{array}$ & $\begin{array}{l}\text { Sustainable } \\
\text { programmes }\end{array}$ & $\begin{array}{c}\text { Broad-Based } \\
\text { BBE }\end{array}$ & $\begin{array}{l}\text { Corporate } \\
\text { governance }\end{array}$ & $\begin{array}{l}\text { Executive } \\
\text { leadership }\end{array}$ & $\begin{array}{l}\text { Women's } \\
\text { empowerment }\end{array}$ \\
\hline 1 & SED2 & 0.553 & 0.003 & -0.174 & -0.023 & -0.131 & 0.052 & 0.227 \\
\hline 2 & $\mathrm{CC} 1$ & 0.545 & 0.039 & -0.093 & 0.055 & -0.266 & -0.025 & 0.144 \\
\hline 3 & SA2 & 0.543 & 0.059 & -0.047 & -0.003 & -0.087 & 0.150 & 0.225 \\
\hline 4 & EE2 & 0.519 & 0.018 & -0.048 & 0.210 & 0.046 & 0.112 & 0.187 \\
\hline 5 & FM1 & 0.443 & 0.044 & -0.097 & 0.113 & -0.169 & 0.013 & 0.250 \\
\hline 6 & SA5 & 0.211 & 0.838 & 0.042 & -0.032 & 0.053 & -0.091 & -0.037 \\
\hline 7 & SP5 & 0.011 & 0.796 & 0.082 & 0.026 & -0.031 & -0.238 & 0.062 \\
\hline 8 & SE5 & -0.045 & 0.771 & -0.040 & 0.018 & -0.100 & -0.027 & -0.006 \\
\hline 9 & SA4 & 0.020 & 0.727 & 0.025 & 0.152 & 0.087 & 0.153 & -0.078 \\
\hline 10 & SE3 & 0.100 & 0.678 & -0.014 & 0.011 & 0.070 & 0.247 & -0.092 \\
\hline 11 & SE4 & -0.127 & 0.661 & -0.065 & -0.111 & -0.118 & -0.007 & 0.117 \\
\hline 12 & SP3 & -0.167 & 0.607 & -0.244 & 0.022 & -0.027 & 0.231 & 0.000 \\
\hline 13 & SA1 & -0.040 & 0.009 & -0.994 & 0.072 & 0.075 & -0.003 & 0.049 \\
\hline 14 & SE1 & -0.067 & -0.033 & -0.712 & 0.103 & -0.075 & 0.016 & 0.088 \\
\hline 15 & SP1 & 0.197 & 0.097 & -0.558 & -0.005 & -0.128 & 0.063 & -0.083 \\
\hline 16 & EL 1 & 0.203 & 0.041 & -0.461 & -0.037 & -0.273 & -0.135 & 0.010 \\
\hline 17 & BE1 & 0.091 & -0.008 & -0.227 & 0.736 & 0.137 & 0.003 & 0.059 \\
\hline 18 & BE5 & -0.058 & -0.069 & -0.073 & 0.677 & -0.297 & -0.002 & 0.080 \\
\hline 19 & BE2 & 0.190 & -0.049 & -0.081 & 0.588 & -0.129 & 0.048 & 0.131 \\
\hline 20 & BE4 & -0.102 & 0.140 & 0.051 & 0.580 & -0.273 & -0.015 & 0.176 \\
\hline 21 & BE3 & 0.020 & 0.305 & 0.147 & 0.448 & -0.003 & 0.123 & 0.196 \\
\hline 22 & CM5 & -0.003 & 0.040 & -0.040 & 0.114 & -0.756 & 0.036 & 0.006 \\
\hline 23 & CG5 & 0.073 & 0.017 & -0.103 & 0.038 & -0.702 & -0.073 & 0.058 \\
\hline 24 & CG3 & -0.106 & 0.020 & -0.135 & 0.180 & -0.684 & 0.083 & -0.025 \\
\hline 25 & CM2 & 0.207 & 0.055 & -0.008 & 0.018 & -0.657 & -0.122 & 0.128 \\
\hline 26 & EL5 & 0.155 & 0.110 & -0.011 & 0.215 & -0.640 & -0.201 & -0.117 \\
\hline 27 & CC5 & 0.078 & -0.060 & -0.013 & -0.052 & -0.625 & 0.117 & 0.108 \\
\hline 28 & CG2 & 0.033 & 0.079 & -0.021 & 0.019 & -0.587 & 0.148 & 0.024 \\
\hline 29 & $\mathrm{CC} 4$ & -0.059 & -0.027 & -0.021 & -0.066 & -0.579 & 0.229 & 0.251 \\
\hline 30 & CG4 & -0.015 & -0.015 & -0.075 & 0.048 & -0.526 & 0.165 & 0.036 \\
\hline 31 & CG1 & 0.172 & -0.012 & -0.227 & -0.138 & -0.493 & -0.106 & 0.084 \\
\hline 32 & SED4 & -0.032 & 0.112 & -0.151 & 0.010 & -0.483 & 0.030 & 0.098 \\
\hline 33 & CM1 & 0.262 & 0.041 & -0.165 & 0.043 & -0.481 & 0.033 & -0.022 \\
\hline 34 & SA3 & 0.087 & 0.107 & -0.068 & 0.053 & -0.278 & 0.495 & 0.015 \\
\hline 35 & CM3 & 0.204 & 0.061 & -0.070 & 0.096 & -0.117 & 0.408 & 0.217 \\
\hline 36 & EE3 & 0.272 & 0.096 & 0.055 & -0.023 & -0.268 & 0.373 & 0.275 \\
\hline 37 & EE4 & 0.081 & 0.042 & 0.082 & 0.152 & -0.215 & 0.353 & 0.310 \\
\hline 38 & WE3 & -0.026 & 0.020 & 0.003 & -0.021 & -0.015 & -0.062 & 0.837 \\
\hline
\end{tabular}




\begin{tabular}{lcccccccc}
\hline Factor & 1 & 2 & 3 & 4 & 5 & 6 & 7 \\
\hline Item & $\begin{array}{c}\text { Social } \\
\text { investment }\end{array}$ & $\begin{array}{c}\text { Stakeholder } \\
\text { engagement }\end{array}$ & $\begin{array}{c}\text { Sustainable } \\
\text { programmes }\end{array}$ & $\begin{array}{c}\text { Broad-Based } \\
\text { BBE }\end{array}$ & $\begin{array}{c}\text { Corporate } \\
\text { governance }\end{array}$ & $\begin{array}{c}\text { Executive } \\
\text { leadership }\end{array}$ & $\begin{array}{c}\text { Womponern's } \\
\text { empowerment }\end{array}$ \\
\hline 39 & WE4 & -0.040 & -0.038 & -0.055 & 0.058 & -0.009 & 0.089 & 0.833 \\
40 & WE2 & 0.147 & 0.025 & -0.011 & 0.050 & 0.015 & 0.071 & 0.783 \\
41 & WE5 & 0.095 & 0.046 & -0.012 & 0.047 & 0.000 & 0.028 & 0.672 \\
42 & WE1 & 0.148 & -0.078 & -0.205 & -0.013 & -0.065 & -0.038 & 0.661 \\
43 & SED5 & 0.043 & -0.005 & 0.051 & 0.268 & 0.018 & -0.034 & 0.590 \\
\hline
\end{tabular}

Notes: Rotation converged in 19 iterations. Loadings in bold represent significant loadings ( $\mathrm{p} \geq 0.350$ ). $\mathrm{BEE}=$ Black Economic Empowerment, SED = socio-economic development, SE = stakeholder engagement, $\mathrm{SA}=$ strategic acumen, $\mathrm{SP}=$ strategic planning, $\mathrm{BE}=$ broad-based black economic empowerment, $\mathrm{EL}=$ executive leadership, $\mathrm{CM}=$ change management, $\mathrm{EE}=$ executive education, $\mathrm{FM}=$ fund management, $\mathrm{CC}=$ corporate culture, $\mathrm{CG}=$ corporate governance, $\mathrm{WE}=$ women's empowerment.

was evidence of discriminant validity among seven of the factors analysed.

\section{Reformulation of the hypotheses}

Several items in the theoretical model expected to measure socio-economic development, corporate culture, strategic acumen, executive education and fund management loaded collectively to form the new factor, social investment. Items expected to measure strategic acumen, stakeholder engagement, strategic planning, and executive leadership loaded onto the new factor, social investment. The new factor, sustainable programmes, was formed because the items expected to measure strategic acumen, stakeholder engagement, strategic planning, and executive leadership loaded onto the new factor.
The variables socio-economic development, strategic acumen, strategic planning, change management, executive education, fund management, and corporate culture were removed from the proposed theoretical model as the exploratory factor analysis process could not verify their discriminant validity. The revised hypotheses are presented in Table 3.

\section{Assessment of goodness of fit}

The following hypotheses were addressed: null hypothesis $\left(\mathrm{H}^{0}\right)$, when the data is normally distributed, and the alternative hypothesis $\left(\mathrm{H}^{\mathrm{a}}\right)$ when the data is not normally distributed.

The null and alternative hypotheses were respectively evaluated by assessing the skewness and the kurtosis of the data, while the chi-

Table 3: Reformulated hypotheses.

Source: Own construction

Hypothesis Factors: Status/reformulation

$\mathrm{H}^{1} \quad$ Social investment: There is a positive relationship between the importance of sustained social investment and good governance.

$\mathrm{H}^{2} \quad$ Stakeholder engagement: There is a positive relationship between the importance of ongoing stakeholder engagement and good governance.

$\mathrm{H}^{3} \quad$ Sustainable programmes: There is a positive relationship between the importance of sustainable programmes and good governance.

$\mathrm{H}^{4} \quad$ Broad-Based Black Economic Empowerment: There is a positive relationship between the importance of B-BBEE policy and good governance.

$\mathrm{H}^{5} \quad$ Executive leadership: There is a positive relationship between the importance of executive leadership and good governance.

$\mathrm{H}^{6} \quad$ Social investment: There is a positive relationship between the importance of sustained social investment and successful women's empowerment.

$\mathrm{H}^{7} \quad$ Stakeholder engagement: There is a positive relationship between the importance of ongoing stakeholder engagement and successful women's empowerment.

$\mathrm{H}^{8} \quad$ Sustainable programmes: There is a positive relationship between the importance of sustainable programmes and successful women's empowerment.

$\mathrm{H}^{9} \quad$ Broad-Based Black Economic Empowerment: There is a positive relationship between the importance of B-BBEE policy and successful women's empowerment.

$\mathrm{H}^{10} \quad$ Executive leadership: There is a positive relationship between the importance of executive leadership and successful women's empowerment.

$\mathrm{H}^{11} \quad$ Good governance: There is a positive relationship between the importance of good governance and successful women's empowerment. 
square $\left(\mathrm{x}^{2}\right)$ value was utilised to determine the associated p-value (Hair et al. 2009). The results of the test for multivariate normality produced a chi-square of 5891.166 and a resulting pvalue of 0.000 . Based on the chi-square value, it was inferred that the data was not multivariate normally distributed, consequently the robust maximum likelihood method of estimation for all the subsequent SEM analyses was employed. Any t-value greater than 1.96 was considered statistically significant $(p<0.05)$ (Shah and Goldstein, 2006). The measurement model represented the degree of success with which the measured variables, i.e., the manifest variables, represented the latent constructs. It also represented the extent to which the structural model demonstrated how the constructs were associated with each other (Hair et al. 2009). The specification of the measurement model indicates conclusively the variables that measure the specified constructs in the structural model using fit indices (Shah and Goldstein, 2006). The assessment of the measurement model was then followed by a similar assessment of the structural model. To assess the extent that the proposed model represented a satisfactory approximation of the data, several fit indices were considered for this model. Table 4 presents the criteria for goodness-of-fit indices and Table 5 presents the fit indices for the measurement model.

The Satorra-Bentler $\mathrm{x}^{2}$ value divided by the degrees of freedom was 1.806, an indicator of a good fit. The root mean square error of approximation of 0.0577 was also regarded as a good fit. The fit indices all provided evidence of a model with a good fit, however, the null hypothesis (for the data fits the model perfectly) was rejected.

\section{Structural model assessment}

To evaluate the identification of the structural model, the size of the covariance matrix relative to the number of estimated coefficients is usually of concern (Hair et al. 2009). The next step was, therefore, to evaluate the goodness-of-fit for the entire model. It was found that the data was not multi-variate normally distributed, and therefore the robust maximum likelihood estimation method was utilised. SEM was used to empirically assess the effectiveness of the relationships between the latent variables in the proposed theoretical model, as opposed to determining a well-fitting model (Hair et al. 2009; Shah and Goldstein, 2006). The robust maximum likelihood estimated method was utilised as the estimation process, since the data was not normally distributed. In the case of the non-normality distribution of the data, the adjusted goodness-of-fit index, and the goodness-of-fit index was not used to evaluate this model fit (Hair et al. 2009; Shah and Goldstein, 2006). This approach signifies that the goal of the statistical analysis was focused on measuring relationships instead of pursuing a good model fit (Hair et al. 2009; Shah and Goldstein,

Table 4: Criteria for goodness-of-fit indices.

Source: Own construction

\begin{tabular}{llcc}
\hline Number & Goodness-of-fit measure & Values & Indicators \\
\hline 1 & 2 /degrees of freedom & $<2$ & Good fit \\
& & $<0.05$ & Close fit \\
\hline 2 & Root mean square error of & $0.05-0.08$ & Reasonable fit \\
& approximation & $>0.08-<0.10$ & Poor fit \\
& & $\geq 0.10-<0.10$ & Unacceptable \\
\hline 3 & $90 \%$ confidence interval for root & $<0.08$ & Upper limit of confidence \\
& mean square error of approximation & & level/good fit \\
& & & Poor fit \\
\hline
\end{tabular}

Table 5: Fit indices for the measurement model.

Source: Own construction

\begin{tabular}{llc}
\hline Number & Measurement techniques & Values \\
\hline 1 & Sample size & 243 \\
2 & Degrees of freedom & 839 \\
3 & Satorra-Bentler scaled Chi-square & $1515.566(\mathrm{p}=0.0)$ \\
4 & SBx 2 Degrees of freedom & $1515.566 / 839=1.806$ \\
5 & Root mean square error of approximation & 0.0577 \\
6 & Expected cross-validation index & 7.147 \\
7 & Comparative fit index & 0.981 \\
8 & Standardised root mean square residual & 0.631 \\
\hline
\end{tabular}


Table 6: Goodness-of-fit indices for the structural model.

Source: Own construction

\begin{tabular}{llc}
\hline Number & \multicolumn{1}{c}{ Item } & Values \\
\hline 1 & Sample size & 243 \\
2 & Degrees of freedom & 839 \\
3 & Satorra-Bentler scaled Chi-square & $1515.566(\mathrm{p}=0.0)$ \\
4 & SBx $^{2} /$ degrees of freedom & $1515.566 / 839=1.806$ \\
5 & Root mean square error of approximation & 0.0577 \\
6 & Expected cross-validation index & 7.147 \\
7 & Comparative fit index & 0.981 \\
8 & Standardised root mean square residual & 0.631 \\
10 & $90 \%$ confidence interval root mean square error of approximation & $0.0531 ; 0.0624$ \\
\hline
\end{tabular}

2006). The indices for the goodness-of-fit for the structural model is presented in Table 6.

The Satorra-Bentler $\mathrm{x}^{2}$ divided by the degrees of freedom ratio was 1.806 . An acceptable value is lower than 2 and can be an indicator of a good fit (Hair et al. 2009). The RMSEA 0.0577 indicated a comparatively close fit, whereas the upper limit of the 90\% confidence interval for RMSEA of 0.0662 was less than 0.08 , and therefore the fit indices provided proof of a model with a good fit (Schumacker and Lomax, 2004). Consequently, the null hypothesis that the data fits the model perfectly was rejected. Although the model does not fit the data perfectly, there was a reasonable fit.

\section{Model amendments}

This step of the data analysis process was to check all the hypotheses and, predicated on the empirical results of the path coefficient, the hypotheses that have been defined could be considered as supported or not supported. Based on the observations and the empirical outcomes, it can be confirmed that not all of the principal relationships in the theoretical model are supported and statistically significant. The model was re-specified by adding, deleting or amending approximate parameters to the proposed theoretical model to establish an improved goodness-of-fit value (Hair et al. 2009).

\subsection{Empirical results}

Several SEM steps were applied to the model to evaluate whether the various hypotheses associated with the model ought to be accepted or rejected, and the results presented below.

\section{Social investment \\ $H^{1}$}

There is a positive relationship between the importance of sustained social investment and good governance. It was found that social investment is not statistically significant to the perceived success of good governance with a path coefficient $=0.214 ;$-value $=1.532 ; \mathrm{p}<$ 0.001 . Hypothesis 1 was therefore rejected.

Not supported

\section{Stakeholder engagement \\ $H^{2}$}

There is a positive relationship between the importance of ongoing stakeholder engagement and good governance. This indicated that stakeholder engagement does not influence the perceived success of good governance with a path coefficient $=0.330 ;$ t-value $=0.717 ; \mathrm{p}<0.001$. Hypothesis 2 was therefore rejected.

Not supported.

\section{Sustainable programmes \\ $H^{3}$}

There is a positive relationship between the importance of sustainable programmes and good governance. It was found that the importance of sustainable programmes is positively related to the intervening variable of good governance with a path coefficient $=0.332$; $\mathrm{t}$-value $=3.606$; $\mathrm{p}<0.001$. Hypothesis 3 was therefore accepted. Supported

\section{Broad-Based Black Economic Empowerment $H^{4}$}

There is a positive relationship between the importance of broad-based black economic empowerment policy and good governance. It was found that the importance of broad-based black economic empowerment is not statistically significant to the perceived success of good governance with a path coefficient $=0.113$; $\mathrm{t}$ value $=1.280 ; \mathrm{p}<0.001$. Hypothesis 4 should, therefore, be rejected.

Not supported

\section{Executive leadership \\ $H^{5}$}

There is a positive relationship between the importance of executive leadership and good 
governance. It was found that executive leadership is positively related to the intervening variable of good governance with a path coefficient $=0.351 ; \mathrm{t}$-value $=2.497 ; \mathrm{p}<0.05$. Hypothesis 5 was therefore accepted.

Supported

\section{Social investment \\ $\mathrm{H}^{6}$}

There is a positive relationship between the importance of sustained social investment and successful women's empowerment. This indicated that social investment is positively related to the dependent variable of successful women's empowerment with a path coefficient $=0.382$; $\mathrm{t}$-value $=3.156 ; \mathrm{p}<0.01$. Hypothesis 6 was therefore accepted.

Supported

\section{Stakeholder engagement \\ $H^{7}$}

There is a positive relationship between the importance of ongoing stakeholder engagement and successful women's empowerment. It was found that stakeholder engagement is negatively related to the dependent variable of successful women's empowerment with a path coefficient $=-0.188 ;$ t-value $=-3.726 ; \mathrm{p}<0.001$. Hypothesis 7 was therefore rejected.

Not supported

\section{Sustainable programmes \\ $H^{8}$}

There is a positive relationship between the importance of sustainable programmes and successful women's empowerment. It was found that sustainable programmes are not statistically significant in relation to the dependent variable of successful women's empowerment with a path coefficient $=-0.032$; $\mathrm{t}$-value $=-0.500 ; \mathrm{p}<$ 0.001 . Hypothesis 8 was therefore rejected.

Not supported

\section{Broad-Based Black Economic Empowerment $H^{9}$}

There is a positive relationship between the importance of B-BBEE policy and successful women's empowerment. It was found that BBBEE policy is positively related to the dependent variable of successful women's empowerment with a path coefficient $=0.326$; $\mathrm{t}$-value $=$ 3.357; $p<0.001$. Hypothesis 9 was therefore accepted.

Supported

\section{Executive leadership \\ $H^{10}$}

There is a positive relationship between the importance of executive leadership and success- ful women's empowerment. This indicates that executive leadership is positively related to the dependent variable of successful women's empowerment with a path coefficient $=0.468$; $\mathrm{t}$-value $=3.415 ; \mathrm{p}<0.001$. Hypothesis 10 was therefore accepted.

Supported

\section{Good governance $H^{11}$}

The hypothesis for good governance states that there is a positive relationship between the importance of good governance and successful women's empowerment. It was found that good governance is not statistically significant to the perceived success of successful women's empowerment with a path coefficient $=0.143$; $\mathrm{t}-$ value $=-1.322 ; p<0.001$. Hypothesis 11 was therefore rejected.

Not supported

Figure 2 illustrates the final model with the hypotheses, path coefficients and t-values.

\section{Conclusions}

The structural equation modelling examined the socio-economic empowerment of women within the renewable energy sector of the Republic of South Africa. This model was predicated on the scenario that, if women were economically empowered, they would to have greater social status. The results revealed that ethical leadership positively influences good governance and successful women's empowerment. The results also indicated that social investment and broadbased black economic empowerment positively influence successful women's empowerment and that sustainable programmes are a positive contributing factor to good governance. This study has the potential to contribute to future developments in the socio-economic empowerment of women by recommending innovative approaches to mainstream gender in the renewable energy sector, thereby improving the lives of communities, and women, in South Africa and elsewhere.

\section{Author roles}

Chris Adendorff and Ric Amansure: Research formulation, contribution to abstract and proofreading

Harvey Keown: data collation, interpretation of results, manuscript write up and submission 


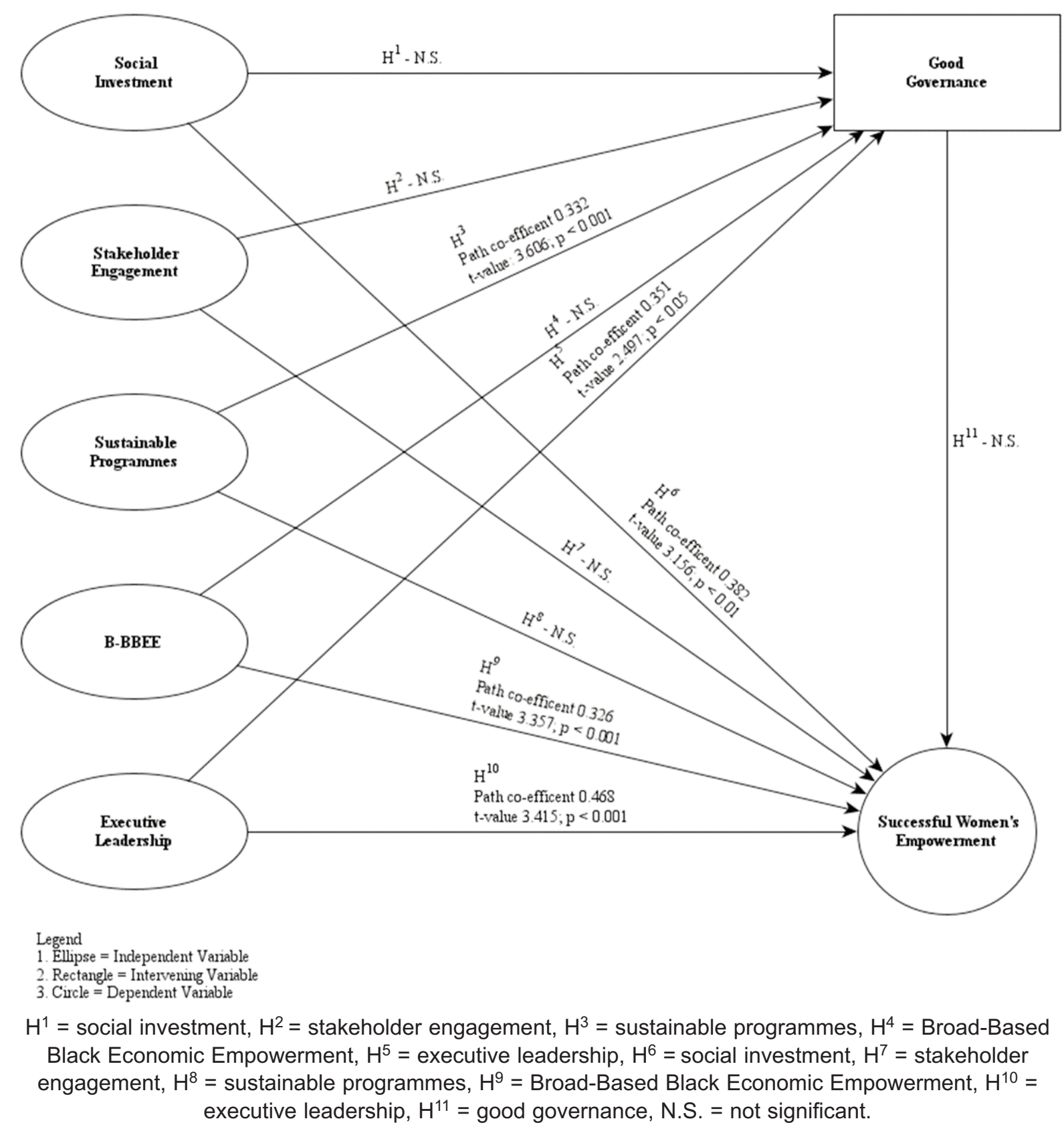

Figure 2: Path diagram of causal relationships: final model. Source: Own construction

\section{References}

Abdi, H. (2003) Factor rotations in factor analyses, Encyclopedia of Social Sciences Research Methods. Thousand Oaks, CA: Sage. Available at: http://www.utdallas.edu/ herve.

Babbie, E. (2010) The Practice of Social Research. 12th edn. Belmont, CA: Wadsworth Cengage.

BusinessTech (2018) IMF cuts South Africas growth forecast for 2018 and 2019, BusinessTech. Available at: https://businesstech.co.za/news/finance/220451/imf-cuts-south-africas-growth-forecast-for-2018-and-2019/(Accessed: 3 February 2018).

Campbell, R. J. (2008) Change management in health care, The Health Care Manager, 27(1), pp. 23-39.

Creamer, T. (2018) Eskom given go ahead to sign stalled deals with renewables IPPs, Engineering News. Available at: http://www.engineeringnews.co.za/article/eskom-given-go-ahead-to-sign-stalled-dealswith-renewables-ipps-2018-02-02 (Accessed: 5 February 2018).

Department of Trade and Industry (2013) Broad-Based Black Economic Empowerment Act. Pretoria: Department of Trade and Industry. Available at: http://www.thedtic.gov.za/financial-and-non-financial-support/b-bbee/b-bbee-codes-b-bbee-acts-strategies-policies/?hilite=\% $27 \mathrm{~b}$ bbee $\% 27 \% 2 \mathrm{C} \% 27$ act $\% 27$. 
Dowd, S. (2018) Guide to successful grant management for NGOs, Guide to Financial Management. Available at: https://www.humentum.org/free-resources/guide/grant-management (Accessed: 24 September 2018).

Drotter, S. (2003) The leadership pipeline, Management Forum Series, 22(2003), pp. 1-7. Available at: www.executiveforum.com.

Eberhard, A., Kolker, J. and Leigland, J. (2014) South Africas renewable energy IPP Procurement Program: success factors and lessons, PPIAF, Washington DC, USA. Washington D.C. Available at: http://www.ee.co.za/article/south-africas-reippp-programme-success-factors-lessons.html.

Engelbrecht, L. (2009) King committee on governance: draft code of governance principles for South Africa - 2009, Institute of Directors in Southern Africa. Johannesburg.

Erb, W. (2008) Characteristics of effective leadership, WJM Associates. Available at: https://www.wjmassoc.com/insight/characteristics-of-effective-leadership-authenticity1/ (Accessed: 23 September 2018).

European Commission (2018) Financial management toolkit for recipients of European Union funds, International Cooperation and Development. Available at: https://ec.europa.eu/international-partnerships/financial-management-toolkit_en (Accessed: 24 September 2018).

Fabrigar, L. and Wegener, D. (2011) Exploratory factor analysis. Oxford.

Fritz, J. M. (2001) Social and economic development, Socioeconomic Development Social Work. Encyclopedia of Life Support Systems.

Global Environmental Facility (2017) A new policy on gender equality, Global Environmental Facility. Washington D.C. Available at: https://www.thegef.org/news/new-policy-gender-equality-gef (Accessed: 3 January 2018).

Grillo, M. (2015) What are practical, meaningful, and actionable ways for HR professionals to gain business experience and acumen, Cornell University. New York.

Hair, J. J. F. et al. (2010) Multivariate data analysis. 7th edn. New York: Pearson Prentice Hall.

Hamilton, K. (2003) Principles of good corporate governance and best practice recommendations, Australian Stock Exchange Corporate Governance Council. Sydney.

Harrington, J. and Voehl, F. (2015) Cultural change management, International Journal of Innovation Science, 7(1): 55-74. Available at: http://tvn.sagepub.com/cgi/content/abstract/4/1/85.

International Finance Corporation (2007) Stakeholder engagement: a good practice handbook for companies doing business in emerging markets. 1st edn, International Finance Corporation. 1st edn. Washington D.C.: World Bank Group. Available at: http://www.ifc.org/.

Kenny, G. (2016) Strategic plans are less important than strategic planning, Harvard Business Review. Sydney: 1-6. Available at: https://hbr.org/2016/06/strategic-plans-are-less-important-than-strategic-planning.

Kilian, A. (2016) South African women in senior corporate positions down four percentage points, Engineering News. Available at: http://m.engineeringnews.co.za/article/south-african-women-insenior-corporate-positions-down-four-percentage-points-2016-08-22/rep_id:4433 (Accessed: 22 August 2016).

Kothari, C. (2004) Research methodology: methods and techniques. 2nd edn. Jaipur: New Age International Publishers.

Marsh, R. M. (2014) Getting ahead and falling behind: a sociological elaboration of Sens theory of human development, Social Science Quarterly, 95(4), pp. 1001-1021.

Martín, I. S. (2016) Pope tells CEOs: if you want to help the poor, empower them!, Crux. Available at: https://cruxnow.com/vatican/2016/12/pope-tells-ceos-want-help-poor-empower/ (Accessed: 25 February 2017).

McGregor, J. (2016) Only one woman was named CEO of a major company in North America in 2015, The Washington Post. Washington D.C. Available at: https://www.washingtonpost.com/news/onleadership/wp/2016/04/21/only-one-woman-was-named-ceo-of-a-major-company-in-north-america-in-2015/ (Accessed: 14 July 2017).

Paramasivan, C. and Subramanian, T. (2009) Financial management. 1st edn. Tamil Nadu: New Age International Publishers.

Presence, C. (2018) PIC believes Steinhoff still has value despite scandal, Independent Online. Available at: https://www.iol.co.za/news/south-africa/western-cape/pic-believes-steinhoff-still-has-valuedespite-scandal-13035769 (Accessed: 4 February 2018).

PricewaterhouseCoopers (2016) Women CEOs: CEO success study examines the degree, nature, and 
geographic distribution of chief executive changes among the worlds 2,500 largest public companies, PricewaterhouseCoopers. Available at: https://www.strategyand.pwc.com/ceosuccess (Accessed: 19 August 2016).

Prince, E. T. (2008) Business acumen: a critical concern of modern leadership development: global trends accelerate the move away from traditional approaches, Human Resource Management International Digest, 16(6), pp. 6-9. doi: 10.1108/09670730810900811.

Ragas, M. (2019) Defining business acumen, Public Relations Journal, 1(13), pp. 1-19.

Schumacker, R. and Lomax, R. (2004) A beginners guide to structural equation modelling. 2nd edn. Edited by D. Riegert. New Jersey: Lawrence Erlbaum Associates Publishers.

Shah, R. and Goldstein, S. M. (2006) Use of structural equation modelling in operations management research: looking back and forward, Journal of Operations Management, 24(2), pp. 148-169.

Stands, S. R. (2015) Utility-scale renewable energy job creation: an investigation of the South African renewable energy independent power producer procurement programme (REIPPPP). Stellenbosch University.

Teasly, D. (2016) Cultural determinism: definition and theory, Introduction to Anthropology. Available at: http://study.com/academy/lesson/cultural-determinism-definition-and-theory.html (Accessed: 25 February 2017).

Walwyn, D. R. and Buys, A. (2014) Research guide for post-graduate students. 22. Pretoria.

Watkins, M. (2013) What is organizational culture? And why should we care?, Harvard Business Review. Available at: https://hbr.org/2013/05/what-is-organizational-culture (Accessed: 25 February 2017).

World Bank (2007) A guide to the World Bank. 2nd edn. Edited by The World Bank. Washington D.C.

Wothke, W. (2010) Introduction to structural equation modelling, SAS Education and Publishing. Washington D.C.: Carolina del Norte. Available at: support.sas.com/training/.

Zinn, S. (2017) Develop transformative leadership for change, Independent Online. Available at: https://www.iol.co.za/capeargus/opinion/develop-transformative-leadership-for-change-11555466 (Accessed: 22 January 2018). 